\title{
Review of Matthew D. Adler's Measuring Social Welfare: An Introduction. New York, NY: Oxford University Press, 2019, 337 pp.
}

\author{
NOEL SEMPLE \\ University of Windsor
}

In a famous 1973 article, Horst Rittel and Melvin Webber proposed a distinction between 'tame' and 'wicked' problems. Tame problems are easy to define even if they are difficult to solve. Winning a game of chess or landing a person on the moon are classic examples of tame problems. Wicked problems cannot easily be defined, and there is often no consensus about the extent to which they have been solved. Public policy questions, according to Rittel and Webber, are almost always wicked:

In a setting in which a plurality of publics is politically pursuing a diversity of goals, how is the larger society to deal with its wicked problems in a planful way? How are goals to be set, when the valuative bases are so diverse? Surely a unitary conception of $a$ unitary 'public welfare' is an anachronistic one. $(1973,168)$

Nevertheless, some have proposed rational and objective ways to make public policy less 'wicked'. Social indicators have been proposed, and governments have been instructed to choose the policies that will maximize the quality of life measured in this way (Raworth 2017, reviewed in this journal: Schokkaert 2019). Cost-benefit analysis seeks to mathematically determine whether proposed regulations are justifiable (Sunstein 2018). Cost-effectiveness analysis makes similar promises regarding public spending decisions (Clark et al. 2018).

There is a better way to 'tame' public policy, according to Matthew D. Adler's compelling new book Measuring Social Welfare: An Introduction. A social welfare function (SWF) aggregates the expected individual welfare effects of alternative policies and recommends one of the alternatives. Apart from some use in tax policy-making, the SWF's impact on real world governments has been limited. This outstanding book may change that by introducing a flexible and powerful tool of normative policy analysis to a broad audience. 
There are two foundational ethical commitments in Adler's SWF approach. The first is consequentialism: choices should be based on an impartial ranking of their expected outcomes. The second is welfarism: the lifetime well-being of individuals, in a certain state of affairs, is what is morally relevant about that state of affairs. Welfare-consequentialism is the combination of these two commitments (23). A welfare-consequentialist government seeks to implement the policies that, overall, can be expected to make individuals' lives go best.

The book thoroughly analyzes the questions that the social welfare function approach must answer before it can give concrete advice on realworld policy questions. At the core of this book are three 'modules', or sets of alternative ways to respond to three key questions.

\section{Module \# 1. A WELL-BeING MEASURE}

First, on what basis can it be said that one individual has more welfare (a better life) than another individual? Adler endorses preferentism, which holds that a person is better off under outcome $x$ than outcome $y$ if that person prefers outcome $x(47)$. What one prefers is not necessarily what one desires, but rather what one would choose if one's preferences were sufficiently well-informed, rational, and self-regarding (Baber 2017). Given sufficient information about an individual's preferences and the extent to which those preferences are fulfilled, it is possible to quantify lifetime welfare for that individual.

Here, as elsewhere, Adler makes the SWF approach as accommodating as possible to different philosophical views. He shows that it is equally compatible with non-preferentist theories of individual welfare, such as objective-good and experientialist accounts (68). However, the apparatus does have its limits. Only welfare accounts permitting robust interpersonal and intrapersonal comparability are compatible with the SWF approach. In order to generate normative conclusions about policy using this tool, it must be possible not only to say that (for example) Sunil's life is better than Sandy's, but also (i) how much better Sunil's life is than Sandy's, and (ii) how much better Sunil's life is in outcome $A$ versus outcome $B$ (11).

\section{MODUlE \#2: A RULE FOR RANKING VECTORS}

Even if one successfully predicts the lifetime welfare of every affected individual under alternative policies, something more is required before one can recommend one of those policies. There will almost always be 
some individuals who do better under policy $A$ and some who do better under policy $B$. How should one aggregate lifetime welfare values in order to determine which policy is more ethically desirable?

Chapter 3 reviews the "landscape" (104) of social welfare functions. The utilitarian SWF is the simplest: it sums up the lifetime welfare figures for all affected individuals and recommends the policy with the higher expected score. This, however, gives no ethical weight to the existence of welfare-inequalities (86). It violates the Pigou-Dalton axiom, which requires approval of any transfer of resources from a better-off individual to a worse-off one, if that transfer is "pure" (having no effect on the total sum of welfare) (98).

The leading alternative which does satisfy Pigou-Dalton is the continuous-prioritarian social welfare function (117). This transforms individual welfare numbers in order to place extra ethical weight on the welfare of those who have less welfare. It does so not because equality of well-being is inherently valuable, but rather, because the claim of a worse-off individual to a unit of welfare is stronger than the claim of a better-off individual to that unit of welfare (122).

The continuous-prioritarian SWF is not the only social welfare function that is fully sensitive to the distribution of welfare. For example, one alternative - the leximin SWF-ranks states of affairs based on the welfare of the worst-off individuals in each of them. If these individuals have equal welfare, the leximin ranking is based on the welfare of the secondworst-off individuals in each, and so forth (86). However Adler argues that only the continuous-prioritarian SWF satisfies the axioms of continuity and separability, and this confers significant practical advantages.

Under the continuous-prioritarian SWF, the welfare of every affected individual counts in the analysis. The "priority parameter" quantifies how much extra weight is placed on the claims of worse-off individuals, relative to the better-off (155). The larger the priority parameter, the more willing the policy-maker would be (for example) to impose a wealth tax that reduces income growth (and aggregate welfare growth), in order to fund social programs increasing the welfare of the worst-off individuals.

\section{MODULE \#3: UNCERTAINTY}

The world is not a simple mechanism offering completely predictable responses to our acts. The SWF approach must therefore engage with uncertainty. Is a policy with an $80 \%$ chance of increasing aggregate welfare 
by 10 units superior to a policy with a 100\% chance of increasing it by 3 units? ${ }^{1}$

Adler's "uncertainty module" (19) allows a social welfare function to make policy advice despite uncertainty. The book even-handedly identifies alternative approaches to uncertainty, along with the ethical axioms which allow one to deductively choose between them. He shows that making decisions based on ex ante Pareto axioms (which focus on individuals' expected welfare) can lead to surprising results. They may require endorsement of a policy imposing risks of very bad outcomes on some individuals (136), which the continuous-prioritarian SWF would clearly reject.

\section{A CASE STUdy}

Chapter 5 illustrates the SWF approach with a hypothetical case study. This is a realistic "risk regulation" (161) policy choice: a new regulation is proposed that would save lives, but also reduce incomes. How much cost (in terms of lost income) is acceptable in order to bring about a certain reduction in mortality?

Adler again adopts a preferentist account of individual welfare. It would be ideal to have a list of numbers representing exactly how well each affected individual's preferences about his or her life would be fulfilled under different policies, but this is impossible. Simplifying assumptions are therefore introduced. Lifetime welfare is estimated using "partially described bundles" of individual attributes-lifespan and income, in this case (163).

Von Neumann/Morgenstern functions are deployed to model preferences under uncertainty. Each individual faces a "lottery" in which the "prizes" (51) are lives of various lengths. If the proposed regulation is introduced, the lottery will offer each individual better odds of living longer, but it will also reduce his or her income (by a flat amount) in each remaining year of the individual's life.

The case study shows that the "breakeven cost" (188)-the largest income loss the government should be willing to accept before rejecting the proposed regulation-depends greatly on the choice between a utilitarian and prioritarian SWF. Under prioritarianism, the breakeven cost becomes higher if wealthy people bear more of the income loss. This is because a

\footnotetext{
${ }^{1}$ Knightian uncertainty (an absence of well-defined probabilities) is something that, according to Adler, the SWF literature has engaged with. However, he puts this to the side as "beyond the scope of this introductory text" (107).
} 
dollar of lost income has a smaller effect on welfare if the individual is wealthy. It is also because an individual's wealth is directly correlated with their welfare, under the assumptions of this model. Losses experienced by them therefore have a smaller effect on the aggregate ethical score. The breakeven cost under prioritarianism also becomes higher if the risk reduction benefits are concentrated on young people, and poor people. These individuals have lower lifetime welfare than older and richer people.

Adler then shows how relaxing certain assumptions (for example, the assumption that every individual has the same preferences as between longevity and income) changes the breakeven point. In addition to showing how different versions of the SWF approach lead to different policy recommendations, chapter 5 also supports the argument, running through the book, that the SWF approach is superior to the currently dominant cost-benefit analysis approach for risk regulation policy analysis. ${ }^{2}$

\section{PARTing Shots}

Chapter 6 elaborates on the role of the SWF approach for the purposes of ethical reasoning within a legal or political system. It also asks what role public opinion should play in fleshing out a social welfare function, and proposes a relatively narrow one. The personal process of reflective equilibrium is the most important tool for making the ethical choices required by the SWF approach, according to Adler (22).

Chapter 7 considers, albeit not comprehensively, two issues arising from the SWF approach. These are (i) policies that change the size of the population, and (ii) whether and how to include information about the extent to which people 'deserve' their welfare level. A Technical Appendix offers a more robust mathematical statement of the arguments developed in the book.

\section{TAming Public Policy?}

Matthew D. Adler did not invent the social welfare function approach. However, over the past decade he has done more than anyone else to establish its ethical foundations and practical utility. In addition to the book under review here, Adler's scholarship on the SWF approach includes a

\footnotetext{
${ }^{2}$ Adler rebuts Louis Kaplow's argument that cost-benefit analysis should be used for most decisions, with the social-welfare function used only for tax and redistribution decisions.
} 
more technical and detailed monograph (2012), an oft-cited collection edited with Marc Fleurbaey (2016), and many articles.

Within the tradition of 'rational-comprehensive' normative public policy analysis (Lindblom 1959), the Adlerian social welfare function is a major leap forward. It surpasses predecessors in its flexibility, its attentiveness to equity, and its sophisticated treatment of uncertainty. Adler makes bold but convincing claims for its versatility, suggesting that the SWF approach can inform any public policy choice (161).

Rittel and Webber may have too quickly dismissed as anachronistic the idea of a "unitary conception of $a$ unitary "public welfare"” (Rittel and Webber 1973, 168). Maximizing aggregate welfare, using a social welfare function, arguably offers just such a conception. This does not mean that public policy will be fully tamed. As the book adroitly demonstrates, even for those who fully accept welfare-consequentialism and the SWF approach, many live philosophical questions remain. Nevertheless, this remarkable work leaves public policy noticeably less wicked than it was before. At a moment of profound political polarization in many countries, Adler's SWF approach is a 'big tent', which can accommodate many who might otherwise not be willing to gather under a single roof and rationally discuss what government should do.

\section{REFERENCES}

Adler, Matthew. 2012. Well-Being and Fair Distribution: Beyond Cost-Benefit Analysis. New York, NY: Oxford University Press.

Adler, Matthew D., and Marc Fleurbaey, eds. 2016. The Oxford Handbook of Well-Being and Public Policy. Oxford: Oxford University Press.

Baber, Harriet E. 2017. Is Utilitarianism Bad for Women? Feminist Philosophy Quarterly 3 (4): Article 6.

Clark, Andrew E., Sarah Flèche, Richard Layard, Nattavudh Powdthavee, and George Ward. 2018. The Origins of Happiness: The Science of Well-Being over the Life Course. Princeton, NJ: Princeton University Press.

Lindblom, Charles E. 1959. The Science of "Muddling Through". Public Administration Review 19 (2): 79-88.

Raworth, Kate. 2017. Doughnut Economics: Seven Ways to Think Like a 21 st Century Economist. White River Junction, VT: Chelsea Green Publishing.

Rittel, Horst W. J., and Melvin M. Webber. 1973. Dilemmas in a General Theory of Planning. Policy Sciences 4 (2): 155-169.

Schokkaert, Erik. 2019. Review of Kate Raworth's Doughnut Economics. Erasmus Journal for Philosophy and Economics 12 (1): 125-132.

Sunstein, Cass R. 2018. The Cost-Benefit Revolution. Cambridge, MA: MIT Press. 
Noel Semple is Associate Professor at the University of Windsor Faculty of Law. His research interests include welfare-consequentialism, access to justice, and civil procedure.

Contact e-mail: <noel.semple@uwindsor.ca>

Website: <www.noelsemple.ca $>$ 